\title{
The Impact of Antihypertensive Agents on Health-Related Quality of Life of Hypertensive Patients
}

\author{
Wajeeha Siddique ${ }^{1}$, Noman $\operatorname{Haq}^{1}$, Maria Tahir $^{2} \&$ Ghulam Razzaque Shahwani ${ }^{1}$ \\ ${ }^{1}$ University of Balochistan, Quetta, Pakistan \\ ${ }^{2}$ Sardar Bahadur Khan Women's University Balochistan, Quetta, Pakistan \\ Correspondence: Noman-ul-Haq, Assistant Professor, Department of Pharmacy Practice, Faculty of Pharmacy and \\ Health Sciences, Pakistan. E-mail: nomanhaq79@gmail.com
}

Received: April 21, 2021; Accepted: May 17, 2021; Published: May 17, 2021

\begin{abstract}
Chronic diseases and their treatment regimen plays a greater role in determining the patient related health outcomes of which one is Health Related Quality of Life. Hypertension itself along with its pharmacotherapy impacts HRQoL of hypertensive patients. The primary objective of the study was to determine the impact of $f$ hypertensive medications on the health-related quality of life among hypertensive patients with the secondary objective to assess which medication significantly affects health related quality of life of hypertensive patients. A quantitative questionnaire based cross-sectional survey was undertaken in outpatient departments of Sandeman Provisional Hospital (SPH) Quetta using an EQ-5D-3L to determine the Health-Related Quality of Life. Convenience Sampling technique was used for data collection. Majority of respondents $(8.7 \%)$ had no problem in first three domains while having some problem in pain and anxiety domains. Following them $7.6 \%$ of patients had some problems in all domains of the EQ5D tool. Moreover. the ACE Inhibitors and Diuretics impacts HRQoL of patients of current study. A total of 263 participated in the study of which (25\%) of the respondents were of age group 48 -75 years old and were married $73.4 \%$ mostly. Majority $(8.7 \%)$ had no problem in first three domains while having some problem in pain and anxiety domains. ACE Inhibitors and Diuretics significantly influence the health status of hypertensive patients acquiring pharmacotherapy. It was concluded that antihypertensive agents have a significant impact on HRQoL of hypertensive patients especially Angiotensin Converting Enzymes and Diuretics, which show significant impact on HRQoL of hypertensive patients. However, it is also suggested to assess the impact of antihypertensive therapies given in combination must also be studied in order to provide health professionals a better understanding of their prescribed regimen to improve patient related health outcomes.
\end{abstract}

Keywords: Hypertension, Health Related Quality of Life, Quetta, ACE Inhibitors, Diuretics, EQ5D-3L

\section{Introduction}

Hypertension is a continuing health problem of immense public health concern globally especially for developing world [1]. In 2010, 1.39 billion individuals globally were living with increased blood pressure, and out of those, 1.04 billion were from Lower Middle-Income Countries and 349 million in Higher Income Countries [2]. It was projected that in the year 2025, the number may increase to $60 \%$ to a total of 1.56 billion [3].

Globally, half of the total death toll caused by stroke and heart disease is due to hypertension. It is the most important risk factor for cardiovascular diseases [3]. Number of interventions, pharmacological and nonpharmacological, have been designed for the purpose of treating hypertension. Despite of having antihypertensives' influence on lowering the risk of stroke, coronary heart disease, congestive heart failure, and mortality they also impose a greater effect on an individual's life style and their Health related quality of life [4, 5]. The pharmacological treatment along with the disease itself has been reported to have side effects that moderately have an adverse effect on an individual's Health-related quality of life especially the psychological domain $[4,6]$, however, the improvement in health related quality of life has also been evidenced by the studies [4]. The consequence of their adverse effect on health related quality of life was reported as poor compliance to antihypertensive treatment and deterioration of symptoms [6].

Health Related Quality of Life therefore can be defined as individuals perceived quality of life representing satisfaction in those areas of life likely to be affected by health status [7-9]. "Health-related quality of life" (HRQoL) integrates aspects of physical, psychological, and social health, as defined by the World Health Organization in 1948 [8]. Patients with chronic conditions often suffer from prolonged physical and psychological distress, which 
deteriorates quality of life and leads to decreased life expectancy $[10,11]$. The development of chronic conditions with established decreased life expectancies is very disturbing for the patients. The complex nature of diseases and sometimes their treatments has stressful effect on social and economic status of the patients. HRQoL can be altered by both the immediate and long-term treatment effects, especially in the chronic disease setting. Even in the controlled status the feeling of being ill heavily imbalances the quality of life (QoL) [7].

There has been considerable number of studies conducted on determining HRQoL of hypertensive patients but hardly any studies have been reported so far which has determined HRQoL of hypertensive patients who have been on the hypertensive pharmacotherapy in Pakistan and especially in the city of Quetta. Therefore, the primary objective of the study was to determine the impact of $\mathrm{f}$ hypertensive medications on the health-related quality of life among hypertensive patients with the secondary objective to assess which medication significantly affects health related quality of life of hypertensive patients.

Understanding the quality of life of hypertensive subjects as well as aspects that pharmacological and nonpharmacological interventions affect them may contribute health care professionals in evolving and applying interventions targeted at improving anti-hypertensive care which would ultimately lead to improved or better health related quality of life $[12,13]$.

\section{Methodology}

\subsection{Study Design and Setting}

A quantitative questionnaire based cross-sectional survey was undertaken in outpatient departments of Sandeman Provisional Hospital (SPH) Quetta. The hospital provides services to majority of the city and provincial population.

\subsection{Participants and Sampling Criteria}

The estimated prevalence of hypertension in Balochistan has never been reported for which the sample size cannot be determined on the basis of prevalence. Addressing the current situation convenience data sampling technique was used and therefore 400 hypertensive patients were approached for the data collection.

Patients of age 18 or above having a documented diagnosis of hypertension for past 6 months or longer and were prescribed one or more antihypertensive medications were included in the study. Moreover, those hypertensive patients who understand Urdu language and were conscious with no mental incapacity and willing to participate were also included in the study. Patients having co morbidities, critically ill or hospitalized were not included in the study. Pregnant ladies were also excluded from the study as these all conditions influence HRQOL along with hypertension and that would make the results biased.

\subsection{Ethical Consideration}

The national bioethical committee guidelines for researches involving humans were followed and therefore was reviewed and approved by Research Committee from Department of Pharmacy Practice, Faculty of Pharmacy and Health Sciences, University of Balochistan. Furthermore, approval was also granted from Medical Superintendent of the Hospital. Patients consent was also given a priority and confidentiality of their information was maintained.

\subsection{Study Instrument}

Health Related Quality of Life was assessed by EuroQoL-5D-3L, which is a generic instrument for the measurement of health outcomes such as HRQoL (EuroQol-Group, 1990). This HRQoL determining tool consists of two parts, of which the first part contains five domains (mobility, self-care, usual activities, pain/discomfort, anxiety/depression), and the second part consists of $20 \mathrm{~cm}$ health meter called as EQ-VAS (Visual Analogue Scale). Each of 5 domains of first part of EQ-5D are measured by three levels of severity i.e. no problems, some or moderate problems and extreme problems. Responses to these five items are used to obtain the weighted EQ-5D index score, which demonstrate health state with a possible range from 0.594 to 1.0. The EQ-VAS (Visual Analogue Scale) consists of two distinct endpoints, the best imaginable health state (score of 100) and the worst imaginable health state (score of zero). EQ-5D was scored in accordance with the criteria designed by EuroQoL.

\subsection{Data Analysis}

The coded data was entered and were analyzed by using SPSS v. 20. Descriptive analysis was used for the patients' characteristics and EQ-5D health status. Chi-square test was applied as an inferential statistical test to determine the impact of antihypertensives on the health-related quality of life of study participants. 


\section{Results}

\subsection{Study Population Characteristics}

Out of 400 patients of hypertension 357 consented to participate in study out of which, 263 patients fulfilled the inclusion criteria. Patient characteristics demonstrates that majority $(25 \%)$ of the respondents were of age group $48-75$ years old and were married $73.4 \%$. Most of the patients $37.3 \%(n=98)$ had no income while $24 \%(n=63)$ of patients had monthly income above 30,000 Pakistani Rupees as displayed in Table 1.

Table 1. Characteristics of Study Participants

\begin{tabular}{|c|c|c|}
\hline Characteristics & Frequency $n=263$ & Percentage (\%) \\
\hline \multicolumn{3}{|l|}{ Age group } \\
\hline $18-27$ & 56 & 21.3 \\
\hline $28-37$ & 42 & 16 \\
\hline $38-47$ & 63 & 24 \\
\hline $48-57$ & 68 & 25 \\
\hline$\geq 58$ & 34 & 12 \\
\hline \multicolumn{3}{|l|}{ Gender } \\
\hline Male & 138 & 52.5 \\
\hline Female & 125 & 47.5 \\
\hline \multicolumn{3}{|l|}{ Marital status } \\
\hline Single & 70 & 26.6 \\
\hline Married & 193 & 73.4 \\
\hline \multicolumn{3}{|l|}{ Ethnicity } \\
\hline Punjabi & 69 & 26.2 \\
\hline Baloch & 79 & 30 \\
\hline Pathans & 77 & 29.3 \\
\hline Sindhi & 17 & 6.5 \\
\hline Others & 21 & 8.0 \\
\hline \multicolumn{3}{|l|}{ Education } \\
\hline Religious education only & 39 & 14.8 \\
\hline Primary & 10 & 3.8 \\
\hline Matric & 32 & 12.2 \\
\hline $\mathrm{FA} / \mathrm{FSc}$ & 33 & 12.5 \\
\hline B. A/B.Sc & 63 & 24.0 \\
\hline Higher education & 86 & 32.7 \\
\hline \multicolumn{3}{|l|}{ Occupation } \\
\hline Unemployed & 53 & 22.2 \\
\hline Self-employed & 32 & 12.2 \\
\hline Govt. servant & 61 & 23.2 \\
\hline Private servant & 21 & 8.0 \\
\hline Housewife & 63 & 24 \\
\hline Student & 33 & 12.5 \\
\hline \multicolumn{3}{|l|}{ Income } \\
\hline No income & 98 & 37.3 \\
\hline Not want to disclose & 52 & 19.8 \\
\hline Less than 10,000 & 13 & 4.9 \\
\hline $10,000-20,000$ & 16 & 6.1 \\
\hline $21,000-30,000$ & 21 & 8.0 \\
\hline Above 30,000 & 63 & 24 \\
\hline \multicolumn{3}{|l|}{ Location } \\
\hline Urban & 170 & 64.6 \\
\hline Rural & 93 & 35.4 \\
\hline
\end{tabular}




\subsection{EQ5D Health Status}

The hypertensive patients receiving pharmacotherapy have reported more than 60 different EQ-5D health states out of which 26 are mentioned in the Table 2 with bulk of respondents $(8.7 \%)$ had no problem in first three domains while having some problem in pain and anxiety domains. Following them $7.6 \%$ of patients had some problems in all domains of the EQ5D tool.

Table 3 shows that majority of the study participants showed no problems in mobility $(52.9 \%, \mathrm{n}=139)$ and in taking care of themselves $(65 \%, \mathrm{n}=171)$. The table also demonstrates that most of the participants have some problems in performing their usual activities $(47.9 \%, \mathrm{n}=126)$. Additionally, bulk of study respondents had moderate ache $(\mathrm{n}=169,64.3 \%)$ and were having moderate level of anxiety and/or depression $(46.4 \%, \mathrm{n}=122)$.

Table 2. Self-Reported EQ5D Health States

\begin{tabular}{llll}
\hline S. No. & Health status & Frequency $\mathbf{n}=\mathbf{2 6 3}$ & Percentage $\mathbf{( \% )}$ \\
\hline $\mathbf{1}$ & 11122 & 23 & 8.7 \\
$\mathbf{2}$ & 22222 & 20 & 7.6 \\
$\mathbf{3}$ & 11111 & 18 & 6.8 \\
\hline $\mathbf{4}$ & 11121 & 16 & 6.1 \\
$\mathbf{5}$ & 11222 & 13 & 4.9 \\
\hline $\mathbf{6}$ & 11112 & 9 & 3.4 \\
\hline $\mathbf{7}$ & 11223 & 9 & 3.4 \\
\hline $\mathbf{8}$ & 12221 & 9 & 3.4 \\
\hline $\mathbf{9}$ & 21122 & 9 & 3.4 \\
\hline $\mathbf{1 0}$ & 21121 & 6 & 2.3 \\
\hline $\mathbf{1 2}$ & 21123 & 6 & 2.3 \\
\hline $\mathbf{1 3}$ & 22232 & 4 & 1.5 \\
\hline $\mathbf{1 4}$ & 12112 & 3 & 1.1 \\
\hline $\mathbf{1 5}$ & 12211 & 3 & 1.1 \\
\hline $\mathbf{1 6}$ & 11123 & 3 & 1.1 \\
\hline $\mathbf{1 7}$ & 11211 & 3 & 1.1 \\
\hline $\mathbf{1 8}$ & 32232 & 3 & 1.1 \\
\hline $\mathbf{1 9}$ & 11221 & 3 & 1.1 \\
\hline $\mathbf{2 0}$ & 22233 & 3 & 1.1 \\
\hline $\mathbf{2 1}$ & 31333 & 3 & 1.1 \\
\hline $\mathbf{2 2}$ & 12212 & 3 & 1.1 \\
\hline $\mathbf{2 3}$ & 21112 & 3 & 1.1 \\
\hline $\mathbf{2 4}$ & 12222 & 3 & 1.1 \\
\hline $\mathbf{2 5}$ & 12323 & 3 & 1.1 \\
\hline $\mathbf{2 6}$ & 11212 & 2 & 0.8 \\
\hline & 11113 & 2 & 0.8 \\
\hline & & & \\
\hline
\end{tabular}

Table 3. EQ5D Domains

\begin{tabular}{lll}
\hline EQ5D Domain & Frequency $\mathbf{n = 2 6 3}$ & Percentage \\
\hline Mobility & 139 & 52.9 \\
I have no problems in walking about & 111 & 42.2 \\
I have some problems in walking about & 13 & 4.9 \\
I am confined to bed & & \\
\hline Self- Care & 171 & 65 \\
I have no problems with self-care & 82 & 31.2 \\
I have some problems washing or dressing myself & 10 & 3.8 \\
I am unable to wash or dress myself & & \\
\hline Usual Activities & 109 & 41.4 \\
I have no problems with performing my usual activities & 126 & 47.9 \\
I have some problems with performing my usual activities & 28 & 10.6 \\
I am unable to perform my usual activities & & \\
\hline
\end{tabular}




\section{Pain / Discomfort}

I have no pain or discomfort

$\begin{array}{ll}59 & 22.4 \\ 169 & 64.3 \\ 35 & 13.3\end{array}$

I have extreme pain or discomfort

Anxiety / Depression

I am not anxious or depressed

I am moderately anxious or depressed

80

30.4

I am extremely anxious or depressed.

61

23.2

\subsection{Impact of Antihypertensive Agents on Health Status}

The Table 4 of the impact of drugs on HRQoL shows ACE Inhibitors and Diuretics significantly influence the health status of hypertensive patients acquiring pharmacotherapy.

Table 4. Association of Antihypertensive agents with Heath Status and VAS Score

\begin{tabular}{llllllll}
\hline Drugs used & Frequency & \multicolumn{2}{l}{ EQ5D-score } & \multicolumn{3}{l}{ VAS-score } \\
\hline ACE Inhibitors & & Mean & SD \pm & P-value & Mean & SD & P-value \\
\hline ARB & 100 & 0.436 & 0.409 & $\mathbf{0 . 0 0 8}$ & 63.60 & 13.65 & $\mathbf{0 . 0 1 2}$ \\
\hline DIU & 47 & 0.566 & 0.327 & 0.198 & 62.45 & 13.14 & 0.255 \\
\hline BB & 53 & 0.370 & 0.440 & $\mathbf{0 . 0 0 5}$ & 61.04 & 16.50 & $\mathbf{0 . 0 0 4}$ \\
\hline CCB & 136 & 0.476 & 0.364 & 0.082 & 62.99 & 12.4 & 0.114 \\
\hline VD & 115 & 0.498 & 0.345 & 0.318 & 64.70 & 12.1 & 0.816 \\
\hline LOP & 71 & 0.514 & 0.329 & 0.768 & 65.86 & 11.03 & 0.290 \\
\hline STA & 149 & 0.470 & 0.389 & 0.061 & 63.87 & 12.5 & 0.099 \\
\hline SSRI & 101 & 0.451 & 0.388 & $\mathbf{0 . 0 1 3}$ & 61.83 & 13.1 & $\mathbf{0 . 0 1 2}$ \\
\hline & 6 & 0.611 & 0.422 & 0.380 & 71.67 & 13.2 & 0.290 \\
\hline
\end{tabular}

\section{Discussion}

The influence of treatment of hypertension on quality of life has been scarcely investigated in population-based surveys. Yan et al found significant improvements in HRQoL during BP control therapies [14]. Similar results were obtained that drug interventions would considerably relieve symptoms, comfort patients' anxiety, and improved their self-reported quality of life. [14,15]. Other studies, in contrast, have reported no or even adverse influences of BP lowering therapies on HRQoL $[14,15]$. Some studies have shown that changes in HRQoL vary by antihypertensive treatment [16].

The study determined that health related quality of life was affected in participants with hypertension under antihypertensive treatment. The association of drug treatment with health-related quality of life has been attributed pharmacological and adverse effects of BP-lowering drugs. The short-term impact of antihypertensive therapy on quality of life can be appraised [14]. Erickson et al and Trivisol reported lower health related quality of life due to symptoms associated with drug treatment $[17,18]$. Chung et al compared three antihypertensive therapies in a randomized clinical trial, while the three treatments showed no difference in the primary outcome, the results showed major differences in health-related quality of life [11]. On the other hand, Antihypertensive treatment has a positive effect on the health-related quality of life indicators, a positive effect that may be due to the drug effect or to the placebo effect [19].

The current study used a universally accepted tool for the assessment of quality of life, which is essential for demonstrating the overall trend and it was found in the present study that antihypertensives have an influence on health-related quality of life. The association of drug treatment with lower quality of life has not been attributed to adverse effects of BP-lowering drugs as a whole or to a group of agents. The TOHMS trial, which followed more than 1000 individuals randomized to four classes of blood agents and placebo for four years, did not find any difference in several scores of quality of life between participants who received active drugs or placebo $[18,20]$.

From the findings of the present study, two of the antihypertensive drug groups i.e., diuretics and angiotensin converting enzymes ACE's, showed significant association with health-related quality of life. In support of significant effect of diuretics on health-related quality of life most of the studies indicate negative effect of diuretics 
on health-related quality of life which may be due to altering urinary frequency, erectile disorder, muscle cramps and fatigue or inadequate symptomatic relief with diuretics drugs [21].

Croog et al evaluated the effect of thiazide diuretic alone or in combination with other antihypertensives lead to decreased health related quality of life scores [22].

However, much of the criticism on quality of life with thiazides is based on the use of (too) high doses [20, 23]. Age dependent significance of diuretic was reported in older patients with better health related quality of life [24].

The studies that have examined the quality-of-life aspects of ACE inhibitors have usually reported favorable results, although most of these studies were not necessarily directed towards patients with hypertension [25]. ACE inhibitors seem to be effective in maintaining or even improving cognitive function through mechanisms other than blood pressure reduction [26]. In particular, patients taking captopril experienced less sexual dysfunction and had higher scores on measures of general well-being and life satisfaction, work performance and cognitive function [27].

In case of supportive therapy statins showed significant effects, Discontinuation of statin treatment was associated with better quality of life [28]. On the other side Statin treatment has beneficial effects on vascular function [29], and generally low frequency of real adverse effects [30], all of which would be mechanisms to affect health related quality of life. One of the octogenarian studies, community-dwelling men showed no significant difference in the health-related quality of life between statin users and nonusers [31].

The TOHMS trial, which followed more than 1000 individuals randomized to four classes of blood agents and placebo for four years, did not find any difference in several scores of quality of life between participants who received active drugs or placebo [18], [20].

\section{Conclusion}

It was concluded by the present study that antihypertensive agents have a significant impact on HRQoL of hypertensive patients. The Angiotensin Converting Enzyme Inhibitors and Diuretics show significant impact on HRQoL of hypertensive patients. However, it is also suggested to assess the impact of antihypertensive therapies given in combination must also be studied in order to provide health professionals a better understanding of their prescribed regimen to improve patient related health outcomes.

\section{References}

[1] Adebusoye, L. A., Ladipo, M. M., Owoaje, E. T., \& Ogunbode, A. M. (2011). Morbidity pattern amongst elderly patients presenting at a primary care clinic in Nigeria. African Journal of Primary Health Care \& Family Medicine, 3(1), 211. Retrieved from https://www.ncbi.nlm.nih.gov/pmc/articles/PMC4565431/

[2] Mills, K. T., Stefanescu, A., \& He, J. (2020). The global epidemiology of hypertension. Nature Reviews Nephrology, 16(4), 223-237. Retrieved from https://www.ncbi.nlm.nih.gov/pmc/articles/PMC7998524/

[3] Ogedengbe, A. (2017). Predictors Of Health Related Quality of Life Among Hypertensive Patients Attending General Outpatient Clinic In Federal Medical Centre Owo, Ondo State. Faculty of Family Medicine.

[4] Ghimire, S., Pradhananga, P., Baral, B. K., \& Shrestha, N. (2017). Factors associated with health-related quality of life among hypertensive patients in Kathmandu, Nepal. Frontiers in cardiovascular medicine, 4: p. 69. Retrieved from https://www.frontiersin.org/articles/10.3389/fcvm.2017.00069/full

[5] Wang, T. J., \& Vasan, R. S. (2005). Epidemiology of uncontrolled hypertension in the United States. Circulation, 112(11), 1651-1662. Retrieved from https://www.ahajournals.org/doi/full/10.1161/CIRCULATIONAHA.104.490599

[6] Williams, G. H. (1998). Assessing patient wellness: new perspectives on quality of life and compliance. American Journal of Hypertension, 11(S8), 186S-191S. Retrieved from https://academic.oup.com/ajh/article/11/S8/186S/151680

[7] Saleem, F., Hassali, M. A., \& Shafie, A. A. (2014). A cross-sectional assessment of health-related quality of life (HRQoL) among hypertensive patients in Pakistan. Health Expectations, 17(3), 388-395. Retrieved from https://onlinelibrary.wiley.com/doi/pdf/10.1111/j.1369-7625.2012.00765.x

[8] Nasim, A., Haq, N. U., Riaz, S., Tahir, M., Saood, M., Yasmin, R., et al. (2018). Health related quality of life (Hrqol)-What it is and how it is measured: Studies from the world and comparison with Pakistan. Indo American Journal of Pharmaceutical Sciences, 5(2), 1086-1095. Retrieved from http://iajps.com/pdf/38.IAJPS38022018.pdf

[9] Tahir, M., Haq, N. U., Nasim, A., Riaz, S., \& Razzaque, G. (2017). Assessment of health related quality of life, 
HRQoL of diabetic patients using Euro-QoL-5D instrument in Quetta, Pakistan. Indo American Journal of Pharmaceutical Sciences, 4(9), 2939-2948. Retrieved from https://issuu.com/iajps/docs/35.iajps35092017

[10] Saleem, F., Hassali, M. A., Shafie, A. A., Atif, M., Haq, N. U., \& Aljadhey, H. (2012). Disease related knowledge and quality of life: A descriptive study focusing on hypertensive population in Pakistan. Southern med review, 5(1), 47. Retrieved from https://www.ncbi.nlm.nih.gov/pmc/articles/PMC3471186/

[11] Chung, S. C. (2010). Health Related Quality of Life in Clinical Studies for Chronic Diseases-Design and Analytical Considerations, University of Pittsburgh. Retrieved from http://dscholarship.pitt.edu/7074/1/[ChungSC]Dissertation.pdf

[12] Kring, D. L., \& Crane, P. B. (2009). Factors affecting quality of life in persons on hemodialysis. Nephrology Nursing Journal, $36(1), \quad 15-24 . \quad$ Retrieved from https://search.proquest.com/openview/502e8171e6fda1aa26320b112c5c8ece/1?pqorigsite $=$ gscholar\&cbl $=45638$

[13] Testa, M. A., Anderson, R. B., Nackley, J. F., Hollenberg, N. K., et al. (1993). Quality of Life and Antihypertensive Therapy in Men--A Comparison of Captopril with Enalapril. New England Journal of Medicine, 328(13), 907-913. Retrieved from https://www.nejm.org/doi/full/10.1056/nejm199304013281302

[14] Yan, R., Gu, H.Q., Wang, W., Ma, L., \& Li, W. (2019). Health-related quality of life in blood pressure control and blood lipid-lowering therapies: results from the CHIEF randomized controlled trial. Hypertension Research, 42(10), 1561-1571. Retrieved from https://www.nature.com/articles/s41440-019-0281-z

[15] Van Hoof, R., Amery, A., Fagard, R., \& Staessen, J. (1990). Quality of life during treatment of hypertensive patients with diuretics. Acta Cardiologica, 45(5), 393-401. Retrieved from http://pascalfrancis.inist.fr/vibad/index.php?action=getRecordDetail\&idt=19388010

[16] Grimm, R. H., Grandits, G. A., Cutler, J. A., et al. (1997). Relationships of quality-of-life measures to longterm lifestyle and drug treatment in the Treatment of Mild Hypertension Study. Archives of Internal Medicine, 157(6), 638-648. Retrieved from https://jamanetwork.com/journals/jamainternalmedicine/articleabstract/623082

[17] Erickson, S., Williams, B., \& L. Gruppen. (2001). Perceived symptoms and health-related quality of life reported by uncomplicated hypertensive patients compared to normal controls. Journal of Human Hypertension, 15(8), 539-548. Retrieved from https://www.nature.com/articles/1001236.pdf?origin=ppub

[18] Trevisol, D., Moreira, L. B., Fuchs, F. D., \& Fuchs, S. C. (2012). Health-related quality of life is worse in individuals with hypertension under drug treatment: results of population-based study. Journal of Human Hypertension, 26(6), 374-380. Retrieved from https://www.nature.com/articles/jhh201148

[19] Mena-Martin, F. J., Martin-Escudero, J. C., Simal-Blanco, F., Carretero-Ares, J. L., Arzua-Mouronte, D., \& Herreros-Fernandez, V. (2003). Health-related quality of life of subjects with known and unknown hypertension: results from the population-based Hortega study. Journal of hypertension, 21(7), 1283-1289. Retrieved from https://journals.lww.com/jhypertension/Abstract/2003/07000/Health_related_quality_of_ life_of_subjects_with.15.aspx

[20] Neaton, J. D., Grimm, R. H., Prineas, R. J., Stamler, J., Grandits, G. A., Elmer, P. J., et al. (1993). Treatment of mild hypertension study: final results. JAMA, 270(6), 713-724. Retrieved from https://jamanetwork.com/journals/jama/article-abstract/407848

[21] Kirushanthan, S. (2019). Health-related quality of life among patients treated with ACE inhibitors and other drugs involved in hypertension treatment. Retrieved from https://www.lsmu.lt/cris/bitstream/20.500.12512/105422/1/FMT\%202019\%20\%28HRQoL\%29.pdf

[22] Croog, S. H., Levine, S., Testa, M. A., Brown, B., Bulpitt, C. J., Jenkins, C. D., et al. (1986). The effects of antihypertensive therapy on the quality of life. New England Journal of Medicine, 314(26), 1657-1664. Retrieved from https://www.nejm.org/doi/full/10.1056/NEJM198606263142602

[23] Vanmolkot, F., De Hoon, J., Ven de Ven, L., \& Van Bortel, L. (1999). Impact of antihypertensive treatment on quality of life: comparison between bisoprolol and bendrofluazide. Journal of Human Hypertension, 13(8), 559-563. Retrieved from https://www.nature.com/articles/1000868.pdf?origin=ppub

[24] Tedesco, M. A., Ratti, G., Mennella, S., Manzo, G., Grieco, M., Rainone, A. C., et al. (1999). Comparison of losartan and hydrochlorothiazide on cognitive function and quality of life in hypertensive patients. American Journal of Hypertension, 12(11), 1130-1134. Retrieved from 
https://academic.oup.com/ajh/article/12/11/1130/242634

[25] Fletcher, A. (1999). Quality of life in the management of hypertension. Clinical and Experimental Hypertension, 21(5-6), 961-972. https://doi.org/10.3109/10641969909061024

[26] Starr, J. M., \& Whalley, L. J. (1994). ACE inhibitors: central actions. Raven Press (ID). https://www.journals.uchicago.edu/doi/abs/10.1086/419057

[27] Fogari, R., \& Zoppi, A. (2004). Effect of antihypertensive agents on quality of life in the elderly. Drugs \& aging, 21(6), 377-393. https://link.springer.com/article/10.2165/00002512-200421060-00003

[28] Teng, M., Lin, L., Zhao, Y. J., Khoo, A. L., Davis, B. R., Yong, Q. W., et al. (2015). Statins for primary prevention of cardiovascular disease in elderly patients: systematic review and meta-analysis. Drugs \& Aging, 32(8), 649-661. Retrieved from https://link.springer.com/article/10.1007/s40266-015-0290-9

[29] Delles, C., Dymott, J. A., Neisius, U., Rocchiccioli, J. P., Bryce, G. J., Moreno, M. U., et al. (2010). Reduced LDL-cholesterol levels in patients with coronary artery disease are paralelled by improved endothelial function: An observational study in patients from 2003 and 2007. Atherosclerosis, 211(1), 271-277. Retrieved from https://www.sciencedirect.com/science/article/pii/S0021915010000602

[30] Horton, R. (2016). Offline: Lessons from the controversy over statins. The Lancet, 388(10049), 1040. https://doi.org/10.1016/S0140-6736(16)31583-5

[31] Strandberg, T.E., Urtamo, A., Kähärä, J., Strandberg, A.Y., Pitkälä, K.H., Kautiainen, H., et al. (2018). Statin treatment is associated with a neutral effect on health-related quality of life among community-dwelling octogenarian men: The Helsinki Businessmen Study. The Journals of Gerontology: Series A, 73(10), 1418 1423. Retrieved from https://academic.oup.com/biomedgerontology/article/73/10/1418/4969227

\section{Copyrights}

Copyright for this article is retained by the author(s), with first publication rights granted to the journal.

This is an open-access article distributed under the terms and conditions of the Creative Commons Attribution license (http://creativecommons.org/licenses/by/4.0/). 